\title{
VINHO SABER: ARTE RELACIONAL EM SUA FORMA COMPLEXA ${ }^{1}$
}

\author{
Prof. Dr. José Luiz Kinceler ${ }^{2}$
}

Palavras-chave: Arte Relacional Complexa, reinvenção do cotidiano, produção de subjetividade

Resumo: Este artigo tem por meta divulgar a pesquisa realizada sobre arte relacional $^{3}$ em sua forma complexa ${ }^{4}$. Esta entende que o fazer arte passa a ser uma atitude ético-estético capaz de ao identificar oportunidades no contexto social, utilizar os referentes de outros campos representacionaisao, provocar descontinuidades crítico-reflexivas na realidade, assim como instalar processos de convívio, que permitam a reinvenção do cotidiano e a produção de novas subjetividades.

\section{Revendo a produção de sentido}

Como reconhecido atualmente, provocar acontecimentos que produzam sentido é de vital urgência para quem está preocupado em gerar proposições em arte que sejam condizentes com nossas necessidades de Representação ${ }^{5}$.

Na medida em que cada contexto cultural amplia a visão de si mesmo, novas formas de representação em arte fazem com que o ato criativo ative atos contínuos de desconstrução ${ }^{6}$ da-

Projeto de Pesquisa CEART- UDESC

2 Professor da Graduação e do PPGAV - Mestrado em Artes Visuais do CEART/ UDESC

${ }^{3} \mathrm{O}$ termo Arte relacional em sua forma complexa parte do que Nicolas Bourriaud definiu como horizonte teórico-prático da arte relacional: "a esfera das relações humanas e de seu contexto social mais que a afirmação de um espaço simbólico autônomo e privado"

${ }^{4}$ Sobre complexidade Edgar Morin pontua que, "existe complexidade, de fato, quando os componentes que constituem um todo (como o econômico, o político, o sociológico, o psicológico, o afetivo, o mitológico) são inseparáveis e existe um tecido interdependente, interativo e inter-retroativo entre as partes e o todo, o todo e as partes." MORIN (2004:14)

${ }^{5}$ Entendemos Representação enquanto capacidade de gerar realidade, de pertencimento a esfera pública. Neste sentido estamos em sintonia com o pensamento de José Luiz Brea quando afirma que, "O trabalho de arte já não tem mais a ver com a representação. O modo de trabalho que chamamos artísticos deve, a partir de agora, consagrar-se a um produzir similar na esfera do acontecimento, da presença: nunca mais no da representação.. LUIS BREA, citado por GALVANO (2001) Disponível: http://www.euskonews.com/01182bk/gaia11803es.html

${ }^{6}$ No sentido derridiano: .A descontrução propõe um exercício do pensar que supõe, mais que tentar escapar-se da metafísica, permanecer nela realizando um trabalho que implique corroer-la desde suas próprias 
quilo que tem pretensão de se instalar na realidade como verdade. Sua forma de atuar reflete um espaço-tempo inserido na realidade que causa uma desestabilização nas regras do jogo representacional. Isto significa abrir o processo criativo a outras estratégias e táticas criativas que provoquem acontecimento, produção de subjetividades que resistam a formas de representação massificadas onde o imaginário do individuo é produzido via imagens calcadas no aparentar. Em fim novas formas em arte que forjem experiências na vida, catalisem acontecimen$\operatorname{tos}^{7}$, ampliem nossa visão e conhecimento de qualquer tema a partir de estratégias criativas que reinventem o cotidiano.

Com este processo acelerado e contínuo de pasteurização do coletivo e homogeneização da cultura, assistimos a disseminação avassaladora de uma forma de vida fundado numa sociedade estruturada pelo consumo que leva o imaginário do individuo a ser formatado pela lógica da imagem sedutora. Frente a esta constatação nos vem a pergunta: Como o sujeito se reinventa e produz novos sentidos? Aqui está a diferença básica e fundamental que insere a arte relacional em sua forma complexa num tipo de representação em arte que desborda limites de exclusão entre arte e mundos de vida possíveis. Uma proposta de arte relacional complexa não está preocupada em criar qualquer tipo de objeto artístico que represente, ou seja, que esteja no lugar de qualquer referente, ou que seja específica por si mesma, obras objetos onde o fluxo de sentido se esgota no exercício de uma breve contemplação reflexiva. Em sua forma complexa a estrutura da proposta provoca descontinuidades a partir de situações reais na qual a ordem simbólica tem a possibilidade de ser questionada a encontrar outros modos de habitar melhor este mundo. Neste sentido, "Vinho Saber" se formou a partir de estratégias ${ }^{8}$ criativas $^{\circ}$ estruturadas para ativar o encontro entre experiências de vida aparentemente distantes. $\mathrm{O}$ dispositivo relacional que acionou esta proposta foi a troca de saberes. Saberes que formam a subjetividade de diferentes sujeitos e que em nossa atual condição e momento correm o risco de se verem aprisionados frente a formas de representação pautadas em desestimular o tempo dedicado a construção de experiências que produzam sentido.

estruturas para levá-las até seu limite; solicitação (no sentido etimológico de fazer tremer) que permita que ditas estruturas mostrem suas fissuras.. (CRAGNOLINI, 1999)

${ }^{7} \mathrm{O}$ acontecimento é uma experimentação que escapa à história, não está determinada por ela, e uma espécie de desvio, uma emergência do novo sentido, um devir, uma ruptura com a sucessão causal e determinista dos trilhos paralelos da história." (LIMA,G. ; TIBURI,M. Que tipo de historia é possível. Disponível em http://www.humanas.unisinos.br/refundamentar/textos/novo/historia.htm

${ }^{8}$ Segundo MORIN, a estratégia encontra recursos, faz contornos, realiza investimentos e desvios; é aberta, evolutiva, enfrenta o imprevisto, o novo. Para alcançar seus fins, se desdobra em situações aleatórias, utiliza o risco, o obstáculo, a diversidade. Tira proveito de seus erros. Precisa de um controle e de uma vigilância, mas também, a todo o momento, de concorrência, iniciativa, decisão e reflexão.. MORIN, CIURANA \& MOTTA (2003: 29) 
Para dar forma ao encontro relacional "Vinho Saber", propriamente dito, um mês antes da data marcada para a troca de saberes, pedi a oito colaboradores de diversas áreas, professores universitários, artistas, sommelier, fotografos, agricultores e outros, que dessem um depoimento sobre a importância do saber ou do vinho em suas vidas. Os depoimentos foram gravados no próprio local da exposição com toda a instalação especialmente montada para as filmagens daquele dia. Estantes equilibradas por garrafões de vinho, garrafinhas em cerâmicas, livros já doados dispostos no porta-garrafas ambientavam o local. Um lençol servindo de entrada e tela de projeção, permitia o acesso de cada colaborador que pronunciava sua visão do tema enquanto trocava seu livro pela garrafinha de cerâmica contento o vinho artesanalmente produzido pelo propositor. Terminada as gravações foi editado um DVD contendo todos os depoimentos articulados com outras imagens que relatam a experiência do autor em seus desdobramentos junto a experiência de fazer vinho: as aulas sobre a cultura do vinho, imagens da construção da parreira, a poda, a fermentação do mosto, a confecção do vinho artesanal. Este vídeo por sua vez foi projetado novamente desde o mesmo lugar em que foi filmado sobre um telão que servia de entrada da instalação durante a exposição relacional.

Para fundamentar o campo de representação em arte relacional na sua forma complexa é conveniente salientar que vários são os artistas e coletivos que atuam de uma forma complexa junto à realidade, questionando o como atuar num determinado contexto, alterando o sentido e o conceito de representação em arte em função de seu trabalho e do marco teórico em que estão vinculadas suas preocupações ético-estéticas. Basta relembrar aqui as propostas ativadas por "The LAND" de Tiravanija, The Quiet Land de Francis Morin, do coletivo Superflex, do grupo de arte colaborativa HAHA, das praticas ativistas e subversivas de Minerva Cuevas, ou do uso do próprio referente quando Eduardo Kac traz a vida a coelha ALBA, e de tantos outros artistas que em suas práticas desconstroem o saber da arte. Em sua forma complexa, a proposta artística proporciona um reencontro crítico-criativo na realidade, uma possibilidade de produzir criativamente espaços intersticiais capazes de provocar novas formas de representação que renegociem as relações diretas entre a arte contemporânea e a vida. Nicolas Bourriaud descreve a sensibilidade coletiva no interior da qual se inscrevem novas formas de práticas artísticas:

A essência da prática artística radicaria então na invenção de relações entre sujeitos; cada obra de arte encarnaria a proposição de habitar um mundo em comum, e o trabalho de cada artista, um rol de relações com 
o mundo que por sua vez geraria outras relações, e assim até ao infinito. ${ }^{9}$

Neste sentido, as ações cotidianas, o artista em constante deriva pela sociedade, os interstícios sociais excluídos ou mal resolvidos, proporcionam o lugar para acontecimentos gerando reflexão crítica sobre um tipo estrutural de representação que tente afirmar imagens de si mesma como verdades naturais. Estas relações permitem que a própria arte se reinvente. $\mathrm{Ou}$ seja, as propostas relacionais em sua forma complexa transitam tanto pelos marcos convencionalizados da instituição Arte quanto se aproximam de acontecimentos e situações inseridos nos mundo de vida cotidiana, disponibilizando ao artista novas possibilidades de atuação na realidade que materializem espaços de vida que gerem participação, reflexão e diálogo a partir do convívio em tempo real. Enfim, geram relações de descontinuidade onde a subjetividade dos sujeitos envolvidos pode ser reconstruída.

Por outro lado, uma proposta de Arte Relacional Complexa somente existe como produtora de representação quando a proposta, em seu acontecer, possibilita a participação e a colaboração por parte do público desestabilizando-o, descolocando-o, fazendo com que seu modo de sentir e perceber este mundo possa ser revisto, por isto se realiza em uma relação dinâmica e aberta. Este devir intensifica a proposta, pois sua existência não está limitada a um final dado hermeticamente pelo artista, ao revés desborda o campo do artista para invadir o campo de experiências de vida de quem está disposto a participar.

$\mathrm{Na}$ Arte Relacional em sua forma complexa, novas estratégias e táticas criativas permitem não somente o acesso físico e intelectual a proposta artística, mas fundamentalmente que o processo criativo seja fruto de um novo jogo representacional. Ou seja, em seu processo criativo o artista assume novas formas para o jogo representacional em arte. O professor de teoria da Arte e crítico da Universidade de Castilla La Mancha, José Luiz Brea, nos alerta a respeito destas novas formas :

Por três vias diferentes as novas práticas artísticas estão assumindo esta responsabilidade. Em primeiro lugar, pela via da narração. A utilização da imagem-técnica e a imagem-movimento, em sua capacidade para

\footnotetext{
${ }^{9}$ La esencia de la práctica artística radicaría entonces en la invención de relaciones entre sujetos; cada obra de arte encarnaría la proposición de habitar un mundo en común, y el trabajo de cada artista, un haz de relaciones con el mundo que a su vez generaría otras relaciones, y así hasta el infinito. Disponível em http://www.um.es/campusdigital/Libros/textoCompleto/poliCultural/05asanchez.pdf, Pág 9, acessado em 12/05/2006. Tradução nossa.
} 
expandir-se num tempo-interno de relato, multiplica as possibilidades da geração de narrativas. Em segundo lugar, pela via da geração de acontecimentos, eventos, pela produção de situações. Mais além da ideia de performance -e por suposto muito mais além da de instalaçãoo artista atual trabalha na geração de contextos de encontro direto, na produção específica de micro-situações de socialização. A terceira via é uma variante desta segunda: quando essa produção de espaços de conversação, de sociabilização da experiência, não se produz no espaço físico, senão no virtual, mediante a geração de uma mediação. $\mathrm{O}$ artista como produtor é: a) um gerador de narrativas de reconhecimento mútuo; b) um indutor de situações intensificadas de encontro e sociabilização de experiência; e c) um produtor de mediações para seu intercâmbio na esfera pública. ${ }^{10}$

Transbordando seus limites e invadindo a cultura de uma maneira ampla, a obra de arte a partir dos anos noventa se afirma como um ato político. Em conseqüência, torna-se um híbrido referencial e vivencial capaz de interagir em diferentes contextos econômicos, sociais e culturais. Por outro lado, uma das mais importantes questões que a arte atualmente se defronta diz respeito à produção de subjetividade tal qual alertada por Guatarri quando postula a necessidade do sujeito repensar suas relações consigo mesmo, com o outro e com o meio ambiente. Nos alerta Guatarri que:

A todas as escalas individuais e coletivas, tanto no que diz respeito a vida cotidiana como a reinvenção da democracia, no registro do urbanismo, da criação artística, do esporte, etc., sempre se trata de interessar se pelo que poderiam ser dispositivos de produção de

\footnotetext{
o Brea, José Luiz - Por tres vías diferentes las nuevas prácticas artísticas están asumiendo esa responsabilidad. En primer lugar, por la vía de la narración. La utilización de la imagen-técnica y la imagenmovimiento, en su capacidad para expandirse en un tiempo-interno de relato, multiplica las posibilidades de la generación de narrativas. En segundo lugar, por la vía de la generación de acontecimientos, eventos, por la producción de situaciones. Mas allá de la idea de performance -y por supuesto mucho más allá de la de instalación- el artista actual trabaja en la generación de contextos de encuentro directo, en la producción específica de micro-situaciones de socialización. La tercera vía es una variante de esta segunda: cuando esa producción de espacios conversacionales, de socialización de la experiencia, no se produce en el espacio físico, sino en el virtual, mediante la generación de unamediación.El artista como productor es: a) un generador de narrativas de reconocimiento mutuo;b) un inductor de situaciones intensificadas de encuentro y socialización de experiencia; y c) un productor de mediaciones para su intercambio en la esfera pública. Disponível em http://www.alfonselmagnanim.com/debats/84/quadern04.htm. Tradução nossa.
} 
subjetividade que vão no sentido de uma resingularização individual e ou coletiva mais bem que no de uma fabricação "mass-mediática" sinônimo de angustia e desesperação. ${ }^{11}$

A partir desta afirmação, identificamos três formas pelas quais a arte relacional em sua forma complexa está agenciando e promovendo produção de subjetividade.

Inicialmente, caso estejamos de fato preocupados em catalisar processos criativos que dêem conta de nossas necessidades de representação em arte, temos que repensar nossas relações com nosso cotidiano, neste momento a produção de descontinuidades no dia a dia se torna vital. Artistas como Gilliam Wearing (Dancing in the Peckham-1994), Gabriel Orozco (Home run-1993), podem nos dar a indicação de como atuar criativamente no cotidiano e simultaneamente problematizar as relações com a instituição arte.

Num segundo momento vislumbrar a possibilidade de deslocamento do marco institucional da arte usando os próprios referentes de uma realidade que a cada dia é mais simulácrica significa um reencontro com a experiência na realidade. A proposta Kissarama 2001 do artista multicultural Asier Perez, nos alerta como a realidade é uma ficção que pode ser manipulada e construída,. Da dupla MALWAL- Mauricio Dias e Walter Riedweg com sua proposta Devotionalia-2003, a qual envolve a questão dos meninos de rua, contribuem decisivamente na diluição dos limites da arte.

Finalmente a realização e participação em processos de convívio onde o tempo da experiência seja sentido como a realização de mundos possíveis. Neste caso o projeto Quietude da Terra $^{12}$ coordenado por Francis Morin realizado em diferentes comunidades nos serve de referencia. O primeiro projeto "A quietude da terra: Vida diária, arte contemporânea e os Shakers" na localidade de Sabbathday Lake, começou em 1995 e terminou em 1996. O segundo projeto intitulado "A quietude da terra: Vida diária, arte contemporânea e Projeto Axé" foi realizado em Salvador-BH iniciando em 1997 e finalizado em 2000. O terceiro projeto começou em 2004, em Luang Prabang, Lao-PDR, e se intitula "A quietude da terra: Arte, Espiritualidade, e vida diária. Os três projetos mesclam formas de representação específicas: educação, espiritualidade e criatividade formam uma complexidade que se manifesta num espaço de convívio das diferenças. Segundo Francis Morin;

\footnotetext{
Guatarri, Felix - Las Tres Ecologías. Madrid : Pretextos, 1996. p. 18

$2 \quad \mathrm{O}$ projeto está disponível em http://www.thequietintheland.org/introduction.php
} 
Cada projeto é estruturado para fornecer um marco para a experiência que apresenta uma estrutura o suficiente para desdobrar-se à medida que os projetos são desenvolvidos. Para realizar cada projeto os artistas trabalham ou convivem por um longo período com a comunidade, que passa a ser definida como um indivíduo, uma família, uma organização, um bairro, uma cidade ou até uma nação. ${ }^{13}$

Outro marco referencial para referendar práticas artísticas fundadas na complexidade e em gerar processos de convívio é a proposta The Land $^{14}$, iniciada em 1998. Conta com a colaboração de vários artistas entre eles, Rirkrit Tiravanija, Prachya Phintong, Kamin Lerdchaprasert, Tobias Rehberger, bem como do coletivo Superflex. The Land atua como local vivenciado, preocupado em materializar novas relações entre o contexto, o sujeito, a coletividade e o meio ambiente.

Estas propostas nos oferecem uma lógica de atuação cultural que expande as formas da arte a acontecerem segundo as necessidades de Representação de nosso tempo

\section{Breves considerações}

Hoje, vivemos numa sociedade onde a informação brota por todos os lugares. Entretanto estar informado requer um tempo deslocado de vida que na maioria das vezes não é traduzido em conhecimento sensível, em produção de novos sentidos e subjetividades. Alimenta se de um simbólico já filtrado enquanto o real não é saboreado.

Consideramos que uma proposta de arte relacional complexa funciona na representação em arte quando três planos, artista, proposta e o público, tem suas áreas de conforto e saberes desestabilizados. Em primeiro lugar está o fato de que a proposta gere uma série de descontinuidades na realidade. De encontrar tempo para a arte. De reconhecer que este mundo te olha e não se deixar ficar submisso a ele. É abrir um entre, um intervalo, uma pausa dinâmica na realidade, um espaço-tempo de atuação capaz de provocar devires. Um interstício para a prática dialógica. Uma proposta quando está estruturada para gerar acontecimento permite a seu propositor rever suas formas de entender o mundo, devires que abrem em potência outras formas de reinventar o cotidiano. São estratégias e táticas criativas que

13 Catálogo do Projeto A quietude da terra, Vida cotidiana, Arte Contemporânea e Projeto Axé, 2000. MUSEU DE ARTE MODERNA DA BAHIA ; Bahia, 2000.

14 A proposta The Land está disponível em http://www.thelandfoundation.org/?About_the_land 
indicam caminhos possíveis para a produção de outras subjetividades capazes de reinventar o sujeito frente a complexidade de nossa atual condição.

Por tanto, a arte relacional em sua forma complexa se estrutura a fim de moldar experiências que se traduzam em acontecimentos. Assim, o propositor depara-se com muitas questões que o leva a repensar as relações institucionais, processuais, de público, de circulação, de cidadania e de representatividade com a consciência de que a Arte é apenas uma forma a mais de construir representatividade no real que se potencializa ao se mesclar com as demais formas de Representação.

Para finalizar e como já referenciado em parágrafos anteriores, a arte relacional em sua forma complexa está mais preocupada em apresentar as diferenças dentro de um espaço de convívio, reconhecendo a necessidade da presença do outro em várias e múltiplas estratégias e táticas criativas que instauram uma zona temporária dialógica capaz de instalar acontecimentos onde o tempo na experiência estética seja efetivamente vivido. O dialogo aberto em busca de alteridade e contaminação entre os sujeitos alcançam formas representativas que são capazes de produzir o encontro e vivencias por meio de formas dialógicas, participativas e colaborativas.

\section{Referencias}

BLANCO, P. CARRILlO, J. CLARAMONTE, J. ESPÓSITO, Marcelo (org.) Modos de hacer. Salamanca: Universidad de Salamanca, 2001

BOURRIAUD, N. Esthétic relationelle. París: Les presses du réel, 1998. Pós-Produción. Buenos Aires: Adriana Hidalgo Editora, 2004

CERTEAU, M. A invenção do cotidiano. Rio de Janeiro: Vozes, 1996.

GUATARRI, F. As três ecologias. Madrid: Pretextos, 1996.

MORIN, E; CIURANA, E.R; MOTTA, R.D. Educar na era planetária: o pensamento complexo como método de aprendizagem no erro e na incerteza humana. São Paulo: Cortez; Brasília, DF: UNESCO. 2003. 111p.

MORIN, F. Catálogo do Projeto A quietude da terra, Vida cotidiana, Arte contemporânea e Projeto Axé, 2000. Bahia: MUSEU DE ARTE MODERNA DA BAHIA, 2000 . 